\title{
Princípios e mecanismos de participação e decisão em sistemas municipais de ensino de Santa Catarina: uma leitura dos artefatos institucionais de democratização da gestão educacional
}

\author{
Principles and mechanisms of participation and decision in the municipal \\ education systems of Santa Catarina: a reading of the institutional artefacts of \\ democratization of educational management \\ Principios y mecanismos de participación y decisión en los sistemas \\ de educación municipal de Santa Catarina: una lectura de los artefactos \\ institucionales de democratización de la gestión educativa
}

ELTON LUIZ NARDI

Orcid iD: http://orcid.org/0000-0001-7706-3585

Universidade do Oeste de Santa Catarina.

MARILDA PASQUAL SCHNEIDER

Orcid iD: http://orcid.org/0000-0003-3019-008X

Universidade do Oeste de Santa Catarina.

ALINE BETTIOLO DOS SANTOS

Orcid iD: http://orcid.org/0000-0001-8933-3845

Universidade do Oeste de Santa Catarina.

DURLEI MARIA BERNARDON REBELATTO

Orcid iD: http://orcid.org/0000-0002-2196-3469 Instituto Federal de Santa Catarina (IFSC) - Campus Itajaí.

\begin{abstract}
Resumo: $O$ artigo tem por objetivo analisar princípios e mecanismos de participação e decisão firmados em bases legais dos sistemas municipais de ensino de Santa Catarina, com o fim de promover a gestão democrática do ensino público na educação básica. Tomando por referência resultados do subprojeto de uma pesquisa em rede, obtidos por meio de exame documental e de questionários, destaca especificidades que caracterizam os sistemas e que demarcam contrastes em termos de participação e decisão. Conclui que coexistem, no conjunto de sistemas, indícios de avanços e refreamentos à participação e decisão.
\end{abstract}

Palavras-chave: Gestão democrática da educação básica. Sistemas municipais de ensino. Participação e decisão. 


\begin{abstract}
The article aims to analyze principles and mechanisms of participation and decision, established in the legal basis of the municipal education systems of Santa Catarina, in order to promote the democratic management of public education in basic education. Referring to the results of the subproject of network research, obtained through documentary examination and questionnaires, it highlights specificities that characterize the systems and that mark contrasts in terms of participation and decision. It concludes that in the set of systems, there is a coexistence of indications of advances and restraints to the participation and decision.
\end{abstract}

Keywords: Democratic management of basic education. Municipal education systems. Participation and decision.

Resumen: El articulo tiene como objetivo analizar los principios y mecanismos de participación y decisión, establecidos en las bases legales de los sistemas educativos municipales de Santa Catarina, con el fin de promover la gestión democrática de la enseñanza pública en la educación básica. Refiriéndose a los resultados del subproyecto de una investigación de red, obtenida a través de un examen documental y cuestionarios, destaca las especificidades que caracterizan los sistemas y que marcan contrastes en términos de participación y decisión. Concluye que, en el conjunto de sistemas, coexisten indicios de avances y restricciones a la participación y la decisión.

Palabras clave: Gestión democrática de la educación básica. Sistemas educativos municipales. Participación y decisión.

\title{
INTRODUÇÃO
}

Investidos do encargo de definir normas para a gestão democrática do ensino público na educação básica, os sistemas de ensino têm sido desafiados a dar conta dessa determinação legal, considerando-se diferentes fatores que concorrem no plano político-institucional, muitos dos quais de dimensões históricas e que remetem à cultura política de cariz patrimonialista que se preserva e se renova no país.

É nesse contexto que, em paralelo à incorporação do princípio da gestão democrática do ensino público na Constituição Federal de 1988, também o Município, então ascendido à posição de ente da Federação ${ }^{1}$, foi incumbido de organizar seu sistema de ensino e definir as mencionadas normas. Do relativo vazio deixado pela Lei de Diretrizes e Bases da Educação Nacional (LDB) - Lei n. 9.394 , de 20 de dezembro de 1996, quanto ao significado e à extensão do princípio, haja vista o modesto referencial de que a gestão democrática salvaguarde a participação dos profissionais da educação na elaboração do projeto pedagógico da escola, a participação das comunidades escolar e local em conselhos escolares ou equivalentes e a promoção de progressivos graus de autonomia da escola pública, conforme firmam os artigos 14 e 15, respectivamente, restou projetado 
sobre os sistemas de ensino não somente a definição de um design institucional útil à democratização da gestão, mas também responder pela legitimidade política das decisões tomadas.

Com nossas atenções voltadas à desenvoltura dos sistemas municipais de ensino no plano político-institucional, o objetivo do presente trabalho é analisar princípios e mecanismos de participação e decisão, conformados em bases legais dos sistemas municipais de ensino de Santa Catarina, com o fim de promover a gestão democrática do ensino público na educação básica. Concebendo tais princípios e mecanismos como opções político-institucionais, a sua identificação ocorreu por meio de análise documental - legislação afeta aos sistemas municipais de ensino catarinenses - e de questionários dirigidos a agentes de participação em espaços institucionalizados, mais especificamente, em conselhos municipais de educação. Tal combinação considera que a legislação porta visões institucionais e pressupostos norteadores da ação e que a leitura dos sujeitos que participam nos oferece elementos que caracterizam as dinâmicas e consequências da participação com a qual convivem.

Os resultados da investigação realizada ${ }^{2}$ derivam da etapa estadual de uma pesquisa em rede, de abrangência nacional, a respeito da gestão democrática do ensino público em sistemas municipais de ensino, da qual participam pesquisadores de instituições de ensino superior de oito estados. ${ }^{3}$

\section{SISTEMAS MUNICIPAIS DE ENSINO CATARINENSES E AS CONDIÇÕES POLÍTICO- INSTITUCIONAIS DE GESTÃO DEMOCRÁTICA DO ENSINO PÚBLICO DA EDUCAÇÃO BÁSICA}

Consoante o objetivo do trabalho, a delimitação empírica da pesquisa compreendeu os municípios de Santa Catarina com sistemas de ensino implantados entre 1997, ano seguinte à aprovação da atual LDB, e 2016, quando da conclusão do levantamento documental, mais especificamente, acerca das condições políticoinstitucionais de gestão democrática do ensino público (princípio constitucional) no âmbito desses sistemas. Para o alcance de um retrato estadual do fenômeno pesquisado, a investigação enfocou cada uma das seis mesorregiões geográficas do estado que, juntas, totalizam 295 municípios, conforme ilustra o Mapa 1. 


\section{Mapa 1 - Divisão mesorregional do Estado de Santa Catarina}

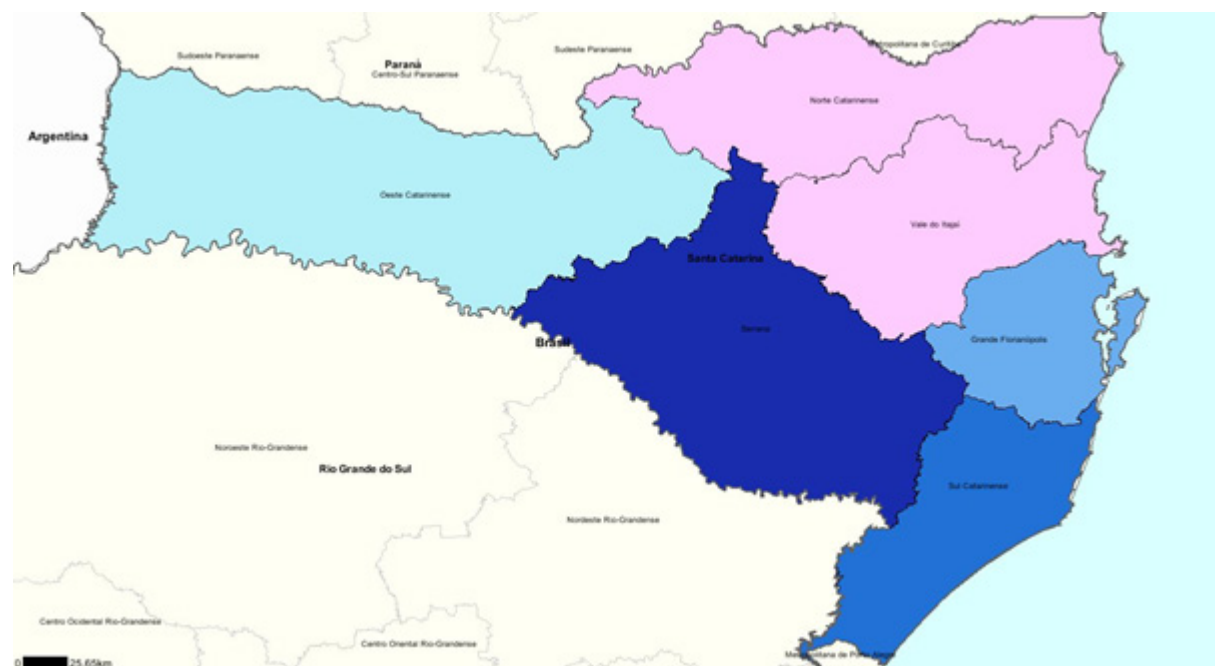

Fonte: IBGE (2019).

A primeira etapa dos trabalhos compreendeu a identificação e a recolha dos documentos, ocorridas por meio da consulta a sites públicos ${ }^{4}$, tendo sido alvos dois conjuntos de artefatos legais: a seção da Lei Orgânica Municipal, que dispõe sobre a Educação e o documento legal que formaliza o sistema municipal de ensino ${ }^{5}$; e outros documentos legais que dispõem a respeito da gestão do ensino público (leis, decretos, portarias e resoluções), inclusive sobre espaços e mecanismos institucionalizados de participação (conselhos, fóruns, conferências, planos de educação, escolha de dirigentes escolares e outros), não raro regulamentados em separado.

De posse dos documentos, foi possível identificar o número de municípios com sistemas de ensino organizados e em atividade, os atos que os instituíram e a data de implantação. De acordo com os dados coligidos, 280 sistemas de ensino foram institucionalizados ${ }^{6}$ ao longo do período enfocado (Mapa 2), o que representa 95\% dos municípios catarinenses.

\footnotetext{
4 Nos casos em que esse acesso não foi possível (25\%), foram estabelecidos contatos com os agentes públicos.

5 A existência desse documento foi fator determinante para a inclusão do município no rol dos pesquisados.

6 São 115 sistemas na mesorregião Oeste Catarinense (97,4\%), 22 na mesorregião Norte Catarinense (84,6\%), 28 na mesorregião Serrana (93,3\%), 52 na mesorregião Vale do Itajaí (96,3\%), 18 na mesorregião Grande Florianópolis $(85,7 \%)$ e 45 na mesorregião Sul Catarinense $(97,8 \%)$.
} 


\section{Mapa 2 - Sistemas Municipais de Ensino institucionalizados - Santa Catarina 1997 a 2016}

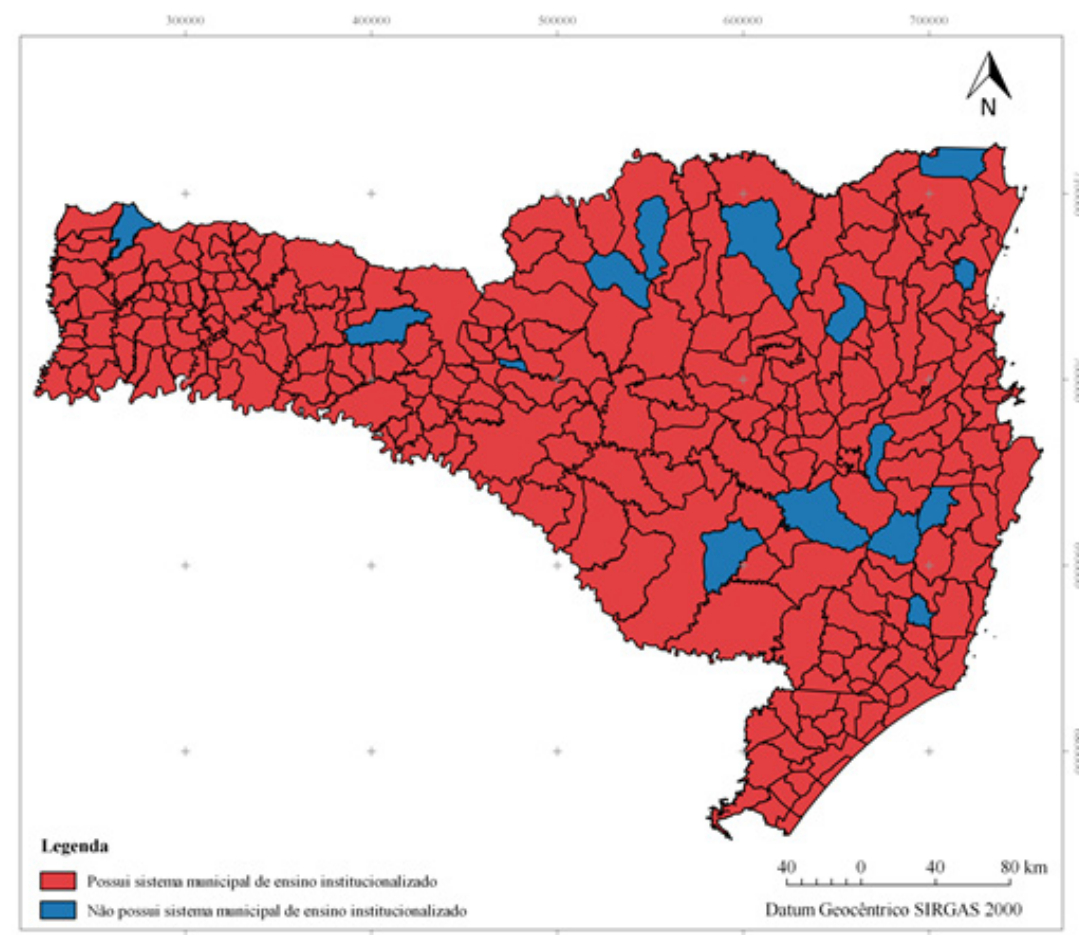

Fonte: Legislação municipal examinada.

A se observar a dinâmica de institucionalização dos sistemas de ensino, um retrato geral em nível estadual possibilita verificar diferentes estágios do processo de formalização desses sistemas. De acordo com os dados ilustrados no Gráfico 1, 42,1\% dos sistemas foram institucionalizados nos três primeiros anos seguintes à aprovação da LDB, sobressaindo-se o ano de 1999, durante o qual foram identificadas 19\% das formalizações. 
Gráfico 1 - Cronologia da institucionalização dos sistemas municipais de ensino em Santa Catarina - 1997 a 2016

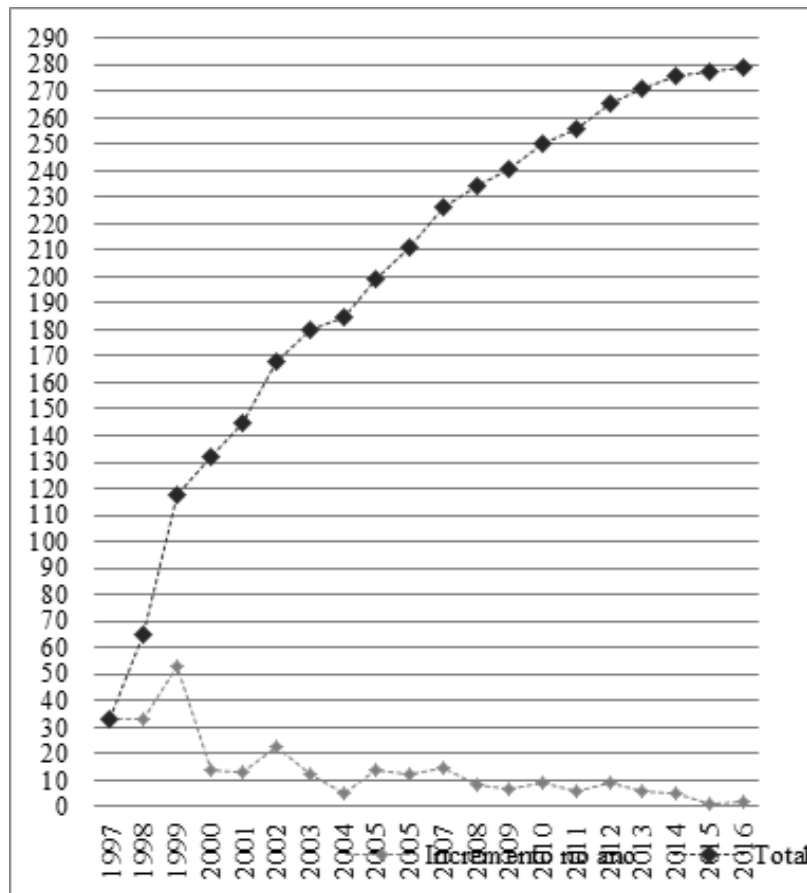

Fonte: Legislação municipal examinada.

Conforme se observa no Gráfico 1, o período compreendido entre 2000 e 2016 é caracterizado por uma progressiva diminuição do número de formalizações, notadamente, em virtude do alcance da quase totalidade dos municípios catarinenses, à exceção do ano de 2002, quando houve um novo impulso nessa direção.

Ato contínuo à identificação do conjunto de municípios com sistemas de ensino, o conteúdo dos documentos coligidos foi submetido à análise, tendo por base contribuições de Bauer (2002) nesse domínio, do que resultou a sistematização de princípios, estruturas, espaços e mecanismos institucionalizados de participação. Ou seja, o mapeamento de normas supostamente firmadas de acordo com as peculiaridades dos sistemas de ensino, conforme determina o art. 
14 da LDB, observada a inclusão dos princípios da participação dos profissionais da educação na elaboração do projeto pedagógico da escola e das comunidades escolar e local em conselhos escolares ou equivalentes. ${ }^{7}$

Considerado esse contexto, do exame da legislação dos sistemas municipais de ensino resultou a identificação dos princípios de gestão democrática do ensino público na educação básica, constantes da Tabela 1.

\section{Tabela 1 - Princípios de gestão democrática do ensino público na educação básica, conformados na legislação dos sistemas municipais de ensino catarinenses - 1997 a 2016}

\begin{tabular}{|c|c|}
\hline Princípios & Frequência \\
\hline 1. Progressivos graus de autonomia pedagógica, administrativa e de gestão financeira às escolas. & 187 \\
\hline 2. Participação da comunidade escolar e local em conselhos escolares ou equivalentes. & 170 \\
\hline 3. Participação dos profissionais da educação na elaboração do projeto político-pedagógico da escola. & 133 \\
\hline $\begin{array}{l}\text { 4. Participação dos profissionais da educação e da comunidade escolar na elaboração do projeto político- } \\
\text { pedagógico da escola. }\end{array}$ & 86 \\
\hline 5. Transparência dos mecanismos pedagógicos, administrativos e financeiros. & 71 \\
\hline 6. Descentralização do processo de gestão educacional e do orçamento. & 45 \\
\hline $\begin{array}{l}\text { 7. Participação efetiva da comunidade escolar na tomada de decisões no âmbito das respectivas unidades } \\
\text { escolares e do sistema municipal de ensino. }\end{array}$ & 33 \\
\hline 8. Escolha de diretores de escola por meio de eleições. & 31 \\
\hline 9. Respeito à autonomia de organização de pais, professores, servidores e estudantes. & 30 \\
\hline 10. Participação das comunidades escolar e local na Associação de Pais e Professores (APP). & 17 \\
\hline 11. Participação da comunidade no planejamento municipal. & 15 \\
\hline 12. Participação efetiva da comunidade escolar na escolha de dirigentes escolares. & 14 \\
\hline 13. Instituição de conselhos escolares com a participação da comunidade escolar, local e regional. & 10 \\
\hline 14. Adoção de planejamento participativo. & 10 \\
\hline 15. Descentralização dos processos educacionais. & 8 \\
\hline 16. Realização de orçamento participativo. & 8 \\
\hline 17. Participação na elaboração do projeto político-pedagógico da rede e das instituições de ensino. & 7 \\
\hline 18. Participação de entidades representativas da população no planejamento das atividades culturais. & 7 \\
\hline 19. Participação na elaboração do projeto político-pedagógico. & 7 \\
\hline 20. Apoio ao funcionamento de grêmios estudantis. & 5 \\
\hline 21. Transparência e visibilidade ao IDEB. & 4 \\
\hline $\begin{array}{l}\text { 22. Instituição de conselhos escolares deliberativos com representantes de todos os segmentos da } \\
\text { comunidade escolar. }\end{array}$ & 3 \\
\hline $\begin{array}{l}\text { 23. Instituição de conselhos escolares deliberativos com representantes de todos os segmentos da } \\
\text { comunidade escolar. }\end{array}$ & 2 \\
\hline
\end{tabular}

\footnotetext{
$7 \quad$ Além dos referidos princípios, há que se considerar o disposto no art. 15 da LDB, sobre progressivos graus de autonomia pedagógica e administrativa e de gestão financeira, a serem assegurados às escolas públicas de educação básica que integram os respectivos sistemas de ensino.
} 


\section{Tabela 1 - Princípios de gestão democrática do ensino público na educação básica, conformados na legislação dos sistemas municipais de ensino catarinenses - 1997 a 2016}

\begin{tabular}{|c|c|}
\hline Princípios & Frequência \\
\hline 24. Participação na elaboração do Plano Plurianual (PPA) e plano Municipal de Educação. & 2 \\
\hline $\begin{array}{l}\text { 25. Liberdade de organização dos segmentos da comunidade escolar em associações, grêmios ou outras } \\
\text { formas. }\end{array}$ & 2 \\
\hline $\begin{array}{l}\text { 26. Eleição direta para o Conselho de Pais e Professores (CPP) ou Associação de Pais e Professores } \\
\text { (APP) e Conselhos, com a participação de todos os segmentos da comunidade escolar. }\end{array}$ & 2 \\
\hline 27. Autonomia da comunidade escolar para definir seu projeto político-pedagógico. & 1 \\
\hline $\begin{array}{l}\text { 28. Participação dos profissionais de educação na elaboração, execução e avaliação do projeto político- } \\
\text { pedagógico da Secretaria Municipal de Educação. }\end{array}$ & 1 \\
\hline $\begin{array}{l}\text { 29. Participação efetiva e democrática da comunidade escolar na definição do projeto político- } \\
\text { administrativo e pedagógico da escola. }\end{array}$ & 1 \\
\hline 30. Escolha de diretores escolares por meio de eleição ou nomeação. & 1 \\
\hline 31. Escolha de diretores de escola por meio de lista tríplice. & 1 \\
\hline $\begin{array}{l}\text { 32. Participação dos profissionais da educação e da comunidade escolar na elaboração, implementação, } \\
\text { monitoramento e avaliação do plano municipal de educação. }\end{array}$ & 1 \\
\hline 33. Participação da comunidade nas decisões e encaminhamentos escolares. & 1 \\
\hline $\begin{array}{l}\text { 34. Participação de representantes das entidades e dos diversos segmentos da sociedade no fórum } \\
\text { municipal da educação. }\end{array}$ & 1 \\
\hline $\begin{array}{l}\text { 35. Autonomia na gestão financeira dos projetos e programas vinculados e desenvolvidos com a } \\
\text { Associação de Pais e Professores (APP). }\end{array}$ & 1 \\
\hline $\begin{array}{l}\text { 36. Participação da Associação de Pais e Professores (APP) nas decisões sobre aplicação de recursos } \\
\text { financeiros. }\end{array}$ & 1 \\
\hline 37. Realização de eleição direta para Associações de Pais e Professores (APP). & 1 \\
\hline TOTAL & 920 \\
\hline
\end{tabular}

Fonte: Legislação municipal examinada.

Com base nos dados da Tabela 1 e tendo em vista o critério de incidência na legislação examinada, é possível agrupar os elementos do conjunto em, ao menos, três subconjuntos ${ }^{8}$. O primeiro compreende os cinco princípios mais incidentes, nos quais sobressai a participação, que figura em três deles (números 2, 3 e 4) e, conforme a concebemos, diz respeito ao direito de decisão no contexto das medidas educacionais. Fundamenta-se no princípio da autonomia, remetendo à capacidade de um grupo ou organização de pessoas para a determinação de si próprios, ou seja, para a tomada de decisões acerca de interesses da coletividade (LIBÂNEO; OLIVEIRA; TOSCHI, 2009). ${ }^{?}$

8 Para o agrupamento dos princípios foram considerados como parâmetros de incidência: 70 ou mais registros (primeiro subgrupo); de 30 a 69 registros (segundo subgrupo); e até 29 registros (terceiro subgrupo).

9 De acordo com Bordenave (1985), a palavra participação vem de parte, de modo que a democracia participativa é aquela em que as pessoas devem sentir que faそ̧em parte dela, têm parte real na sua condução e, portanto, tomam parte e sentem parte na construção de uma nova sociedade. 
Desse rol de princípios que evoca a participação, o mais incidente na legislação examinada versa sobre as figuras da comunidade escolar e local em conselhos escolares ou equivalentes (número 2), mencionado na legislação de 170 sistemas de ensino $(60,7 \%$ dos municípios catarinenses com sistema de ensino próprio), o que denota sintonia com o preconizado pelo artigo 14, inciso II, da LDB, e pela Meta 19, estratégia 19.5, do atual Plano Nacional de Educação (PNE). Já no que se refere ao terceiro e ao quarto princípios desse primeiro subconjunto, o que está em pauta é a participação na elaboração do PPP da escola. Embora ambos incidam sobre o mesmo mecanismo de participação, a diferença reside nos sujeitos da participação. Enquanto o princípio 3 se refere aos profissionais da educação e da comunidade escolar, o 4 reporta somente aos primeiros.

Acerca dessa particularidade, diferentemente do que se verifica nos três princípios mais recorrentes, a diferença demarcada no conteúdo do quarto mais incidente amplia o que a base nacional determina (artigo 14 da LDB e Meta 19, estratégia 19.6, do PNE), constituindo-se em dado marcadamente positivo. Afinal, a inclusão da comunidade escolar como protagonista da elaboração do PPP, considerando-se por óbvio uma concepção sociocrítica de gestão, resulta em um alargamento favorável da diretriz legal. Ademais, corrobora nossa hipótese de que se trata de um posicionamento político diferenciado sobre o tema o fato de a adoção do princípio em um mesmo sistema não vir acompanhada da outra versão (número 3). Tal premissa está alicerçada no fato de que a soma das duas versões alcança um percentual $78,2 \%$ do universo pesquisado.

Também integrante do primeiro subconjunto, temos a autonomia das escolas nos âmbitos pedagógico, administrativo e financeiro, definida no artigo 15 da LDB, assim como na Meta 19, estratégia 19.7, do PNE. Nesse caso, trata-se do princípio mais corrente na legislação, estando presente em $66,8 \%$ dos sistemas municipais de ensino e equivalendo a $20,3 \%$ do total de princípios identificados.

Por fim, acerca do quinto princípio, que dispõe sobre transparência, a presença dessa diretriz pode ser verificada na legislação de um quarto dos municípios pesquisados. Trata-se de um princípio que tem a ver com a legitimação das ações praticadas pela esfera pública, visando à redução do distanciamento que a separa da população, como meio para superar obstáculos impostos por governos centralizadores.

Um segundo subconjunto de princípios contidos na Tabela 1 compreende aqueles com incidência média na legislação consultada. Trata-se dos princípios de número 6 a 9, que figuram em, aproximadamente, $10 \%$ do universo de sistemas de ensino pesquisados. Nesse caso, os temas alvos são descentralização, participação em processos decisórios, escolha de diretores escolares e liberdade de organização dos segmentos escolares. 
Acerca desse segundo subconjunto, é possível destacar duas características gerais. A primeira é que se trata de princípios não vinculados, necessariamente, à base legal nacional ${ }^{10}$, embora sua menção e defesa sejam recorrentes na literatura educacional e, portanto, imprimem à sua adoção um enriquecimento do repertório de princípios. Também, porque versam sobre dimensões diferentes de uma mesma matéria: a democratização da gestão do sistema e da escola pública.

A segunda característica é que esses princípios têm clara incidência sobre a escola e o sistema de ensino como um todo, ali contidas uma das mais caras figuras do debate a respeito da democratização da escola no país: a eleição de diretores escolares. Sua presença tímida nas bases normativas dos sistemas municipais de ensino permite-nos levantar a hipótese de que, a despeito da defesa massiva na literatura acerca da importância desse recurso, as opções políticas municipais em Santa Catarina ainda tendem a seguir ao largo desse princípio.

Se considerarmos a forte tradição conservadora que demarca a gestão pública da educação no país, podemos dizer que a adoção desse mecanismo constitui uma medida de peso em termos de marcos políticos e institucionais democráticos, um termômetro do processo de democratização nos sistemas de ensino. Afinal, conforme destaca Dourado (2000, p. 84), “as eleições diretas para diretores têm sido, historicamente, uma das modalidades tidas pelos movimentos sociais, e particularmente, pelo movimento dos professores como uma das formas mais democráticas."

Por fim, referimo-nos ao terceiro subconjunto, demarcado nos princípios escalonados entre os números 10 a 37 que, por um lado, possuem baixa incidência na legislação dos municípios pesquisados - entre uma e 17 vezes - e, por outro, evidenciam a diversificação de princípios na legislação dos sistemas municipais. Vale destacar que a diversificação, no que diz respeito à sua incidência, é desejável por denotar observância às peculiaridades locais e à valorização de desenhos político-institucionais próprios.

Também nesse subconjunto, o princípio da participação tem incidência significativa na legislação examinada, haja vista que o termo figura diretamente em 13 dos 28 princípios desse agrupamento. Vale destacar que a presença desse princípio na legislação municipal tem um significado importante, pois, ao se tratar da essência da descentralização, uma questão central reside, de acordo com Bordignon (1993, p. 150), “[...] no deslocamento do eixo de poder, permitindo que as políticas públicas e as decisões sejam formuladas via participação.” É exatamente nessa perspectiva que localizamos o sentido que assume a participação nesse subconjunto.

10 O princípio de número sete, diferentemente dos demais que compõem o segundo subconjunto, tem maior aproximação com princípios conformados na legislação nacional. 
Os demais princípios, também sintonizados com esta perspectiva participação e descentralização de poder - tocam temas, como planejamento, organização dos segmentos de estudantes e trabalhadores em educação, espaços de participação e deliberação, gestão financeira, entre outros. Figuram, igualmente, princípios menos sintonizados com a essência da participação, como se verifica no de número 21.

Da análise dos princípios identificados na legislação dos sistemas municipais, uma primeira observação diz respeito à inobservância, por parcela dos municípios, dos princípios da gestão democrática do ensino público consagrados na LDB (princípios de número 1 a 3). Relativamente aos demais, os dados analisados permitem-nos, por um lado, argumentar sobre certo alargamento do leque de ideias-força relacionadas à democratização da gestão educacional, e, por outro, afirmar que, entre as mesorregiões, há diferenças significativas quanto à adoção dos princípios arrolados na Tabela 1 , seja no que se refere à tipologia ou à frequência.

Partindo do pressuposto de que, da observância aos princípios de gestão democrática conformados na legislação dos municípios deve decorrer a correspondente materialização, foi possível identificar um conjunto variado de espaços e mecanismos institucionalizados de participação, por meio dos quais seja possível a intervenção das pessoas nos processos dinâmicos que constituem ou modificam a história da sociedade (BORDENAVE, 1985). Com base no exame da legislação, identificamos a formalização de 16 tipos de espaços ou mecanismos de participação, conforme consta na Tabela 2.

Tabela 2 - Espaços e mecanismos de participação, conformados na legislação dos sistemas municipais de ensino catarinenses - 1997 a 2016

\begin{tabular}{|l|c|}
\hline \multicolumn{1}{|c|}{ Princípios } & Frequência \\
\hline 1. Conselho Municipal de Educação & 280 \\
\hline 2. Projeto Político-Pedagógico & 274 \\
\hline 3. Plano Municipal de Educação & 273 \\
\hline 4. Conselho Escolar & 224 \\
\hline 5. Associação de Pais e Professores (APP) & 102 \\
\hline 6. Fórum Municipal de Educação & 92 \\
\hline 7. Eleição de diretores & 55 \\
\hline 8. Grêmio Estudantil & 50 \\
\hline 9. Conferência Municipal de Educação & 47 \\
\hline
\end{tabular}


Tabela 2 - Espaços e mecanismos de participação, conformados na legislação dos sistemas municipais de ensino catarinenses - 1997 a 2016

\begin{tabular}{|l|c|}
\hline \multicolumn{1}{|c|}{ Princípios } & Frequência \\
\hline 10. Congresso, seminário e/ou plenárias & 24 \\
\hline 11. Seminário Municipal de Educação & 5 \\
\hline 12. Congresso Escolar Constituinte & 4 \\
\hline 13. Planejamento Participativo & 2 \\
\hline 14. Assembleia Escolar & 2 \\
\hline 15. Eleição de coordenadores & 1 \\
\hline 16. Eleição ou nomeação de diretores TOTAL & 1 \\
\hline
\end{tabular}

Fonte: Legislação municipal examinada.

O conjunto de dados constante da Tabela 2 também pode ser analisado com base no critério de incidência, do que resulta a constituição de três subconjuntos de elementos que configuram espaços ou mecanismos de participação ${ }^{11}$. Dessa perspectiva, um primeiro subconjunto comporta os quatro primeiros elementos, um segundo reúne os elementos distribuídos entre os itens 5 a 9 e, por fim, um terceiro subconjunto compreende os demais espaços e mecanismos de participação constantes da Tabela (de 10 a 16).

$\mathrm{Na}$ direção apontada, foi possível constatar que os três primeiros espaços ou mecanismos de participação encontram-se presentes na legislação de, praticamente, todo o universo de sistemas pesquisados (entre 98\% e 100\%), não havendo, portanto, distinções acentuadas quanto à frequência do Conselho Municipal de Educação, do Projeto Político-Pedagógico e do Plano Municipal de Educação ${ }^{12}$ entre as seis mesorregiões.

Já em relação ao Conselho Escolar, o quarto elemento do primeiro subconjunto, sua frequência na legislação examinada é de $80 \%$. Embora esse espaço de participação represente uma importante conquista para a escola pública, também determinada pela LDB, sua formalização em nível de sistemas municipais catarinenses ainda constitui uma tarefa em aberto.

No segundo subconjunto, que representa uma faixa intermediária de frequência na legislação examinada, composta pelos itens de 5 a 10 da Tabela 2, figuram os seguintes espaços e mecanismos de participação: Associação de Pais e

11 Foram considerados os seguintes parâmetros de incidência: 100 ou mais registros (primeiro subgrupo); de 40 a 109 registros (segundo subgrupo); e até 39 registros (terceiro subgrupo).

12 Sobre o Plano Municipal de Educação, afora sua conhecida importância no planejamento das políticas educacionais, é possível que o alto percentual também se deva à acentuada a mobilização, desde 2001, para a aprovação dos planos subnacionais. 
Professores (APP); Fórum Municipal de Educação; Eleição de diretores; Grêmio Estudantil; $e$ Conferência Municipal de Educaşão.

A $A P P$, entidade privada, sem fins lucrativos, e que tem por objetivo a integração entre escola e comunidade e o apoio à escola no desenvolvimento de suas atividades, é uma associação com larga tradição no estado. É fato que há muito funciona como entidade representativa dos segmentos de pais e de professores, com forte presença em processos decisórios, embora se concentrando em questões relacionadas à manutenção e à assistência financeira da escola. Com essas peculiaridades, a $A P P$ constitui um espaço de participação, razão pela qual sua inobservância em parte dos documentos municipais possa não ser considerada a sua ausência nas respectivas redes de ensino.

Quanto ao Fórum Municipal de Educaşão e à Conferência Municipal de Educação, que constituem espaços complementares no que diz respeito às suas funções, importa destacar que o primeiro tem a função de representar os diferentes segmentos da sociedade e se constituir em veículo de comunicação entre a comunidade e o poder público. Também tem por atribuição a coordenação das Conferências Municipais de Educaşão.

De acordo com os dados colhidos, o Fórum Municipal de Educação consta na legislação de cerca de 33\% dos municípios catarinenses. Por ser um espaço relativamente recente em Santa Catarina, é provável que o advento da promulgação da lei que dispõe sobre o atual PNE mobilize a esfera municipal para o debate local, com vistas ao levantamento de prioridades, metas e estratégias. Disso nossa hipótese de que os Fóruns Municipais de Educaşão serão progressivamente instalados em todos os municípios do estado.

No que diz respeito à Conferência Municipal de Educação, contemplada em, aproximadamente, $17 \%$ dos municípios da mesorregião, embora tenha por objetivo constituir-se em espaço de debates sobre a situação da educação nos municípios e a proposição de diretrizes para a política municipal de educação, a hipótese que levantamos é de que, semelhantemente ao que ocorre com o Fórum, esse espaço ainda é pouco experienciado nos municípios, tendo sido mobilizado mais significativamente a partir de 2009, com o advento da primeira Conferência Nacional de Educação (Conae) de 2010.

Relativamente ao mecanismo Eleição de diretores, previsto na legislação de 19,6\% dos sistemas municipais de ensino, sua incidência varia em cada uma das mesorregiões geográficas do estado de Santa Catarina, conforme evidencia o Gráfico 2. 


\section{Gráfico 2 - Percentuais de registros da eleição para diretores de escola em sistemas municipais de ensino, enquanto mecanismo de participação - mesorregiões de Santa Catarina (2016)}

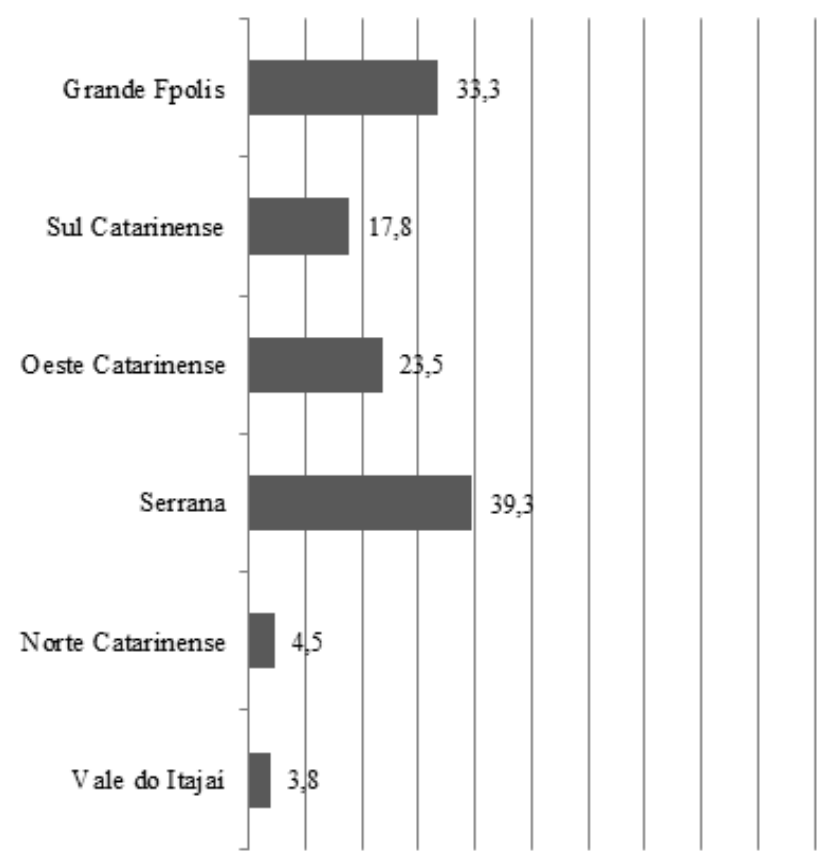

Fonte: Legislação municipal examinada.

Conforme apurado, os percentuais de municípios que possuem nos ordenamentos legais a eleição para o provimento do cargo de diretor são baixos nas escolas municipais catarinenses e, comparativamente, destacam-se em duas mesorregiões. Concebendo o processo de democratização da gestão da escola pública na perspectiva da socialização da participação política e do poder, a eleição para diretores constitui um importante recurso de participação dos usuários da escola pública (PARO, 2000). Contudo, os dados ilustrados despertam suspeitas quanto ao valor creditado a esse recurso em termos de democratização da gestão, e, por extensão, à disposição política corrente nos sistemas de ensino com vistas a prover condições concretas para a socialização da participação política e do poder, conforme entendemos com base em Coutinho (2003).

Embora a eleição não seja o único recurso a materializar um processo de democratização da gestão escolar, abdicar de sua adoção não somente parece enfraquecer a sintonia com o princípio da gestão democrática, conforme dispõe a Constituição Federal de 1988 (inciso VI do art. 206), a LDB de 1996 (art. 14) e, 
ainda, o PNE de 2014 (art. $9^{\circ}$ ), como também oferece indícios de refreamentos a uma perspectiva de democratização. Por essas razões, os dados acerca da eleição para o provimento do cargo de diretor nas diferentes mesorregiões catarinenses constituem mostra de que, mesmo no plano legal, a baixa incidência dessa via de provimento reforça indícios de que a livre indicação como forma usual de escolha de dirigentes escolares, presente em $80,4 \%$ dos municípios pesquisados, reafirma o centralismo e o verticalismo nas decisões nos sistemas municipais de ensino. Tempera essa reafirmação o fato de que 36,4\% desse conjunto $(29,3 \%$ dos municípios pesquisados) estabelecem o provimento na forma de cargo em comissão, portanto de livre nomeação e exoneração, nos termos do art. 37, inciso II, da Constituição Federal de 1988, sendo possível verificar os maiores percentuais dessa forma nas duas mesorregiões que registram o menor percentual de adoção da via eleitoral: Norte Catarinense, com 31,8\%; e Vale do Itajaí, com $42 \%{ }^{13}$

Sobre o Grêmio Estudantil, identificado em cerca de 19\% da base legal examinada, sua menor presença no conjunto de normas atinentes à gestão democrática do ensino público é, sem dúvida, um dado preocupante, seja pelo fato de ser um espaço voltado aos interesses coletivos dos estudantes, seja pelo papel que pode desempenhar em termos de processos decisórios da escola.

Por fim, o terceiro subconjunto, composto pelos espaços e mecanismos descritos nos itens 10 a 16 da Tabela 2, comporta: espaços de participação destinados a estudos e debates de temas da área educacional (congressos, seminários, plenárias e assembleias escolares), entendidos como lugares e oportunidades de participação dos sujeitos sociais para a tomada de decisão sobre os rumos da educação municipal; e mecanismos de participação endereçados ao planejamento e à escolha de dirigentes e coordenadores escolares.

Além da baixa incidência dos espaços e mecanismos de participação, podemos destacar outras características relativas a esse terceiro subconjunto, quais sejam: há mais espaços do que mecanismos de participação; os itens mais frequentes na legislação examinada não estão presentes em sistemas de ensino de todas as mesorregiões; os diversos espaços e mecanismos do subconjunto concentram-se em três mesorregiões (Oeste Catarinense, Serrana e Grande Florianópolis), o que as caracteriza pela maior diversidade de espaços e mecanismos de participação, seja no terceiro subconjunto, seja no conjunto geral listado na Tabela 2.

13 Nos demais $51,1 \%$ dos municípios pesquisados, que estabelecem a função de direção escolar como função de confiança acessível a membros efetivos do magistério público municipal, prepondera a fixação de percentuais de gratificação proporcionais ao número de estudantes matriculados nas respectivas escolas. 
Ante o exposto, é possível inferir que, à conta do disposto na legislação dos sistemas municipais de ensino catarinenses, as redes municipais tendem ao mínimo em termos de opções de espaços e mecanismos de participação institucionalizados, ressalvados casos em algumas mesorregiões nas quais há elementos que compõem um quadro mais ampliado e diversificado. É o caso das mesorregiões Oeste Catarinense, Serrana e Grande Florianópolis, embora envolvendo um conjunto reduzido de municípios. Ou seja, esse quadro mais ampliado e diversificado é, em grande medida, determinado pela entrada em cena de espaços e mecanismos do terceiro subconjunto da Tabela 2. Todavia, embora esse subconjunto comporte ao menos outras seis possibilidades de espaços e mecanismos, são poucos os municípios que as firmaram na legislação de seus sistemas de ensino.

De modo geral, a correlação entre o conjunto de mecanismos de participação referido na legislação examinada e os eixos nucleares informados pelos princípios permite-nos apontar quatro enfoques sintonizados com as ideias de participação e decisão, a saber: descentralização do poder decisório; definição de políticas, com destaque ao princípio do planejamento participativo; interlocução sociedade e Estado; e organização política, aduzindo o envolvimento político em coletivos da comunidade escolar (NARDI, 2019).

Por fim, a segunda etapa dos trabalhos da pesquisa compreendeu a organização e submissão de questionário a membros do conselho municipal de educação - um representante do segmento de docentes da rede municipal de ensino e um representante da sociedade civil -, com o propósito de levantar informações que permitissem uma caracterização das dinâmicas de participação nos sistemas de ensino e, em face dessa caracterização, uma análise geral acerca dessas dinâmicas, na interface com as condições político-institucionais.

O processo de recolha das informações da segunda etapa ocorreu por meio de formulário eletrônico submetido aos sujeitos participantes da pesquisa, no ano de 2018. Embora o plano inicial fosse pela identificação de, ao menos, um representante de cada segmento, por município, o acesso às informações viabilizou o levantamento de 312 nomes com os respectivos endereços de e-mail, para os quais foi enviado o questionário ${ }^{14}$. Findo o prazo de recepção das respostas, foram registrados 116 retornos $^{15}$, o que representa $37 \%$ do conjunto de sujeitos identificado. Os dados apontam que 51,6\% dos conselheiros exercem a função há até dois anos, enquanto os demais acumulam uma experiência superior a dois

\footnotetext{
14 O questionário foi composto por questões de múltipla escolha e questões abertas.

15 Do conjunto de respondentes, 65,5\% são representantes do segmento dos docentes das redes municipais de ensino.
} 
anos. Todavia, 53,3\% dos respondentes declaram não ter participado de qualquer formação para atuar no Conselho, fosse ela anterior ou durante o exercício da função.

Um primeiro bloco de questões versou, basicamente, sobre oportunidades para a participação da sociedade nos processos de tomada de decisão a respeito de assuntos da educação pública municipal. Chamados a se posicionarem a respeito da existência dessas oportunidades em seus municípios, 30\% dos respondentes referiram serem muitas e adequadas as oportunidades de participação e outros $30 \%$ disseram existirem apenas algumas oportunidades adequadas de participação. As demais leituras são indicativas de certa descrença no potencial das oportunidades existentes nos municípios, endereçadas à participação da sociedade no trato de assuntos relacionados à educação pública.

Contudo, quais razões estariam ancorando esses posicionamentos? As justificativas colhidas dos conselheiros tendem a certa polarização. Entre os que questionam a adequação das oportunidades, ainda que admitida a existência delas, as razões apresentadas vertem, basicamente, sobre a inefetividade da participação da sociedade na gestão do sistema de ensino, diferenciando-se um pouco da gestão das escolas, em relação a qual são reconhecidos alguns avanços, ainda que frequentemente entrecortados em virtude do maior ou menor compromisso dos gestores com a causa da democratização.

São denunciados, por um lado, o frágil respaldo político que possuem os espaços de participação - destacando-se o conselho municipal de educação -, e as condições concretas de participação das pessoas, especialmente quanto à compatibilidade de horários e à qualidade do envolvimento possibilitado. Por outro, e mais incisivamente, são denunciadas a falta de interesse ampliado da comunidade por esses espaços e de, ipso facto, por temas e debates de foro público; bem como uma tendente desvalorização, pelo poder público, do papel legalmente atribuído a esses espaços, o que abre caminho para um duplo efeito deletério à democratização da gestão: inobservância ao princípio da autonomia; e persistência na centralização do poder decisório nas mãos dos agentes da administração pública.

Já entre os que entendem haver muitas oportunidades adequadas de participação em seus municípios, os argumentos concentram-se no fato de existirem diversos lugares de participação formalmente concebidos nos quais diferentes segmentos possuem assentos e podem deliberar com responsabilidade e compromisso, em diálogo com o poder público. Nesse polo, participação, representatividade e deliberação são termos pulsantes e enlaçados para caracterizar, de um ângulo positivo, as dinâmicas de participação nos sistemas de ensino pesquisados. 
Em suma, a polarização revelada nas justificativas destaca o vínculo entre participação e descentralização do poder, uma vez que o fator determinante do processo de democratização da ação do Estado e de suas práticas institucionalizadoras reside, justamente, no tratamento dado ao exercício do poder decisório (JACOB, 2000).

Explicitadas as leituras acerca das oportunidades de participação correntes nos municípios catarinenses com sistemas próprios de ensino, o segundo bloco de questões voltou-se aos espaços e mecanismos de participação existentes na esfera local, assim como à qualidade do seu funcionamento, conforme ilustra o Gráfico 3. Por um lado, tal leitura possibilitou identificar o conjunto de espaços e mecanismos ${ }^{16}$ mais recorrentes, com base na compreensão dos conselheiros. Por outro, viabilizou indiciar o grau de confiança dos respondentes acerca da qualidade do funcionamento desses espaços e mecanismos de participação.

Gráfico 3 - Percentuais de espaços e mecanismos de participação e de seu adequado funcionamento nos sistemas municipais de ensino catarinenses, segundo posicionamentos de conselheiros (2018)

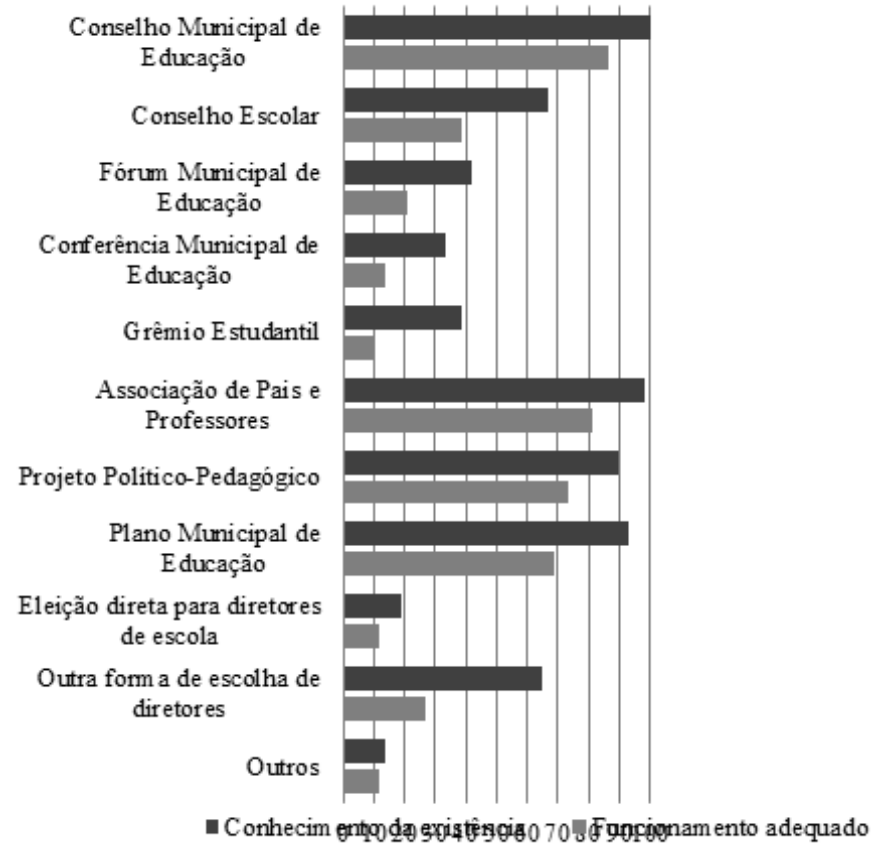

Fonte: Questionários.

16 Os espaços e mecanismos de participação listados no questionário foram os identificados na legislação municipal examinada. 
De acordo com os dados ilustrados no Gráfico 3, são quatro os espaços ou mecanismos de participação mais conhecidos pelos respondentes. Além do próprio Conselho Municipal de Educação, figuram o Projeto Politico-Pedagógico, o Plano Municipal de Educação e a Associação de Pais e Professores.

Conforme apontado, os três primeiros possuem alta incidência na legislação examinada, enquanto a Associação de Pais e Professores possui média incidência, embora seja uma organização tradicional nas redes públicas do estado. Todavia, a leitura dos respondentes acerca do funcionamento adequado desses espaços e mecanismos projeta justamente sobre essa Associação um alto grau de confiança, comparativamente aos demais. As reservas quanto a esse conjunto recaem mais incisivamente sobre o Projeto Politico-Pedagógico e o Plano Municipal de Educação. Entre a maioria dos demais espaços e mecanismos de participação - conselho escolar, fórum municipal de educação, conferência municipal de educação, grêmio estudantil e outras formas de escolha de diretores -, os percentuais de menção ao adequado funcionamento situam-se entre 20 e 40 pontos percentuais inferiores aos da menção à existência desses mesmos espaços e mecanismos. A eleição direta para diretores de escola é um dos mecanismos de participação sobre o qual os respondentes que o conhecem atribuem maior confiança quanto ao seu adequado funcionamento. Nesse caso, a diferença percentual é inferior a sete pontos.

No quadro das razões que justificam a efetividade dos espaços e mecanismos de participação com funcionamento adequado para fins de democratização da gestão da educação pública municipal, sobressaem destaques à participação que proporcionam e à cobertura em termos de abrangência no âmbito do sistema de ensino. Em menor escala, é mencionado o alcance em termos de deliberações oportunizadas, havendo algumas relações com a transparência e exercício do controle social. De modo geral, não são identificadas razões que assinalem qualidades políticas e sociais mais acentuadas à participação que se processa nos espaços e mecanismos destacados, a despeito de certa recorrência na menção de atributos funcionais desses espaços e mecanismos.

Por fim, o terceiro e último bloco de questões versou sobre projeções com vistas ao reforço das condições de democratização da gestão educacional no âmbito dos sistemas municipais de ensino. Como parte desse bloco, também foram enfocados desafios quanto a avanços na democratização da gestão nos municípios pesquisados.

Nessa direção, os conselheiros foram inquiridos, inicialmente, quanto à possibilidade de reforço às condições de democratização da gestão educacional no município, por meio da instalação de outros espaços ou mecanismos de participação. A esse respeito, 40,6\% dos respondentes entendem que sim e outros $44 \%$ admitem que talvez essa possa ser uma via relevante, haja vista 
não estarem seguros de que a melhoria das condições de democratização passe, necessariamente, por tal providência. Sobre quais seriam esses outros espaços e mecanismos, as referências são imprecisas, havendo algum destaque à implantação da eleição direta para diretores de escola e, em outra perspectiva, à qualificação dos atuais espaços e mecanismos de participação.

Acerca de quais seriam os desafios a serem superados em seus municípios, a fim de que haja avanços na democratização da gestão do ensino público na educação básica, seja em nível de sistema de ensino, seja em nível de escola, as respostas dos conselheiros consultados vertem, basicamente, em duas direções: qualificação das condições de participação política da sociedade e que, portanto, implica o poder decisório sobre assuntos educacionais no município; e ampliação dos investimentos públicos em educação.

Conforme se pode inferir, ambas as direções tocam mais diretamente a ação do Poder Público. No primeiro caso - qualificação das condições de participação política da sociedade -, é insinuada a necessidade de instauração de oportunidades de participação em que os sujeitos sociais possam envolverse mais profundamente com processos decisórios, sem perder de vista alguns apelos quanto à necessidade de uma maior conscientização da população sobre a importância da participação social. Dentre as menções constantes dos comentários, sobressai o recurso da eleição direta para diretores escolares (mencionada por cerca de $20 \%$ dos respondentes), recurso esse menos lembrado pelos respondentes quando referida a efetividade dos espaços e mecanismos de participação nos sistemas de ensino de seus municípios, conforme ilustrado no Gráfico 3. Frequentemente, os comentários fazem associação dessas medidas à necessidade de serem ultrapassados interesses político-partidários ainda muito arraigados na gestão pública, inclusive na educação.

Em relação ao desafio da ampliação dos investimentos públicos em educação, os comentários registrados referem, principalmente, à necessidade de melhorias nas condições de trabalho e na remuneração dos profissionais da educação, reconhecendo nessas iniciativas o potencial de repercussão na qualidade do trabalho escolar e na gestão educacional. Encontram-se associados a esse desafio os investimentos em qualificação profissional, inclusive, no plano da gestão educacional.

A se considerar recursos institucionais de participação atualmente existentes e a qualidade do seu funcionamento, assim como as opiniões colhidas sobre a demanda por novos lugares e oportunidades de participação, as percepções dos depoentes indiciam haver distanciamentos entre o campo das práticas de 
gestão e o disposto nos atuais ordenamentos legais dos sistemas municipais de ensino acerca de espaços e mecanismos de participação, mais precisamente, quanto ao alcance e à efetividade desses espaços e mecanismos.

\section{CONSIDERAÇÕES FINAIS}

Posto o desafio da materialização da gestão democrática e a aposta de que esta perspectiva de gestão seja respaldada legalmente pelos sistemas de ensino, o presente estudo pretendeu trazer à cena o retrato das iniciativas dessa natureza no âmbito dos sistemas municipais de ensino catarinenses. Ainda que as providências institucionais afins constituam fenômeno relativamente recente, estudos da área oportunizam perceber que tal movimento encerra um quadro de complexidade e contradições.

Com base nas relações entre as condições político-institucionais e as leituras acerca das dinâmicas que informam a gestão democrática do ensino público no âmbito dos sistemas municipais de ensino pesquisados, as reflexões tecidas possibilitam visibilizar esse quadro à medida que explicitam uma intrincada combinação de alguns avanços no plano das condições formais de participação e de marcas que denotam imposição de limites e até retrocessos à dinâmica de democratização, se pensada enquanto processo de socialização da participação política e socialização do poder (COUTINHO, 2003).

Consoante os resultados apresentados, a investigação possibilitou evidenciar que, por um lado, pesa sobre parte dos sistemas municipais de ensino catarinenses a inobservância de alguns princípios de gestão democrática consagrados nacionalmente e, por outro, uma frágil correspondência desses princípios com espaços e mecanismos de participação que, segundo alguns depoimentos, sejam politicamente qualificados para se constituírem em recursos mais efetivos para a materialização da gestão democrática da educação pública. Possibilitou, ainda, deslindar que entre os espaços e mecanismos de participação já reconhecidos por seu significado em um projeto democrático de gestão, alguns têm sua legitimidade questionada por parcela dos agentes de participação.

Tendo por base o pressuposto da participação enquanto prática de decisão (SHIROMA; CAMPOS, 2006), temos que às pistas de refreamento identificadas no domínio normativo somam-se outros fatores presentes no domínio das práticas de gestão que fomentam efeitos semelhantes, repercutindo conjuntamente na qualidade do processo de democratização da gestão da educação nos municípios pesquisados. Todavia, a par do que poderíamos chamar de denúncias quanto ao atravessamento de condições que desfavorecem um envolvimento mais concreto e politicamente efetivo dos usuários da escola pública em processos decisórios, os 
resultados da consulta aos sujeitos sociais também mostram que segue existindo um tom de aposta na gestão democrática do ensino público na educação básica, por vezes corroborado por um aparato político-institucional que parece destoar das frequentes condições triviais presentes na maioria dos municípios do conjunto, de que são mostras alguns contrastes regionais no interior do estado de Santa Catarina.

Neste décor, compreendemos que o empenho coletivo na promoção da participação política, dada sua essencialidade para o projeto de democratização, conforme a concebemos no plano das lutas por uma escola pública e de qualidade para todos, segue sendo tema atual e fundamental a esse projeto, sem que se perca de vista a contenção à participação desempenhada pelas formas institucionais, por meio do seu enquadramento aos limites de uma democracia de curto alcance.

\section{REFERENNCIAS}

BAUER, Martin, W. Análise de conteúdo clássica: uma revisão. In: BAUER, Martin, W.; GASKELL, George (ed.). Pesquisa qualitativa com texto, imagem e som: um manual prático. Tradução de Pedrinho A. Guareschi. 2. ed. Petrópolis: Vozes, 2002. p. 189-217.

BORDENAVE, Juan E. Diaz. O que é participação? São Paulo: Brasiliense, 1985.

BORDIGNON, Genuino. Gestão democrática do sistema municipal de educação. In: GADOTTI, Moacir; ROMÃO, José Eustáquio (org.). Município e educação. São Paulo: Cortez, 1993. p. 135-172.

BRASIL. Constituição da República Federativa do Brasil, 1988. Brasília: Senado Federal, 1988. Disponível em: http://www.planalto.gov.br/ccivil_03/ constituicao/constituicao.htm.

Acesso em: 15 ago. 2015.

BRASIL. Lei no 9.394, de 20 de dezembro de 1996. Estabelece as diretrizes e bases da educação nacional. Diário Oficial [da] República Federativa do Brasil, Poder Executivo, Brasília, DF, 21 dez. 1996. Seção 1, p. 27833-27841.

BRASIL. Lei no 13.005, de 25 de junho de 2014. Aprova o Plano Nacional de Educação - PNE e dá outras providências. Diário Oficial da União, Poder Executivo, Brasília, DF, Edição Extra, no 120-A, 26 jun. 2014. Seção 1, p. 1-8. 
COUTINHO, Carlos Nelson. A democracia na batalha das ideias e nas lutas políticas do Brasil de hoje. In: FÁVERO, Osmar; SEMERARO, Giovanni (org.). Democracia e construção do público no pensamento educacional brasileiro. 2. ed. Petrópolis: Vozes, 2003. p. 11-39.

DOURADO, Luiz Fernandes. A escolha de dirigentes escolares: políticas e gestão no Brasil. In: FERREIRA, Naura Carapeto (org.). Gestão democrática da educação: atuais tendências, novos desafios. 2. ed. São Paulo: Cortez, 2000. p. 77-95.

JACOB, Pedro Roberto. Educação, ampliação da cidadania e participação. Educação e Pesquisa, São Paulo, v. 26, n. 2, p. 11-29, jul./dez. 2000.

LIBÂNEO, José Carlos; OLIVEIRA, João Ferreira de; TOSCHI, Mirza Seabra. Educação escolar: políticas, estrutura e organização. 8. ed. São Paulo: Cortez, 2009.

NARDI, Elton Luiz. Gestão democrática do ensino público na educação básica: dimensões comuns e arranjos institucionais sinalizados em bases normativas de sistemas municipais de ensino. Educar em Revista, Curitiba, v. 34, n. 68, p. 123 136, mar./abr. 2019.

OZGA, Jenny. Investigação sobre políticas educacionais: terreno de contestação. Tradução Isabel Margarida Maia. Porto: Porto Editora, 2000.

PARO, V. H. Gestão democrática da escola pública. 3. ed. São Paulo: Ática, 2000.

SHIROMA, Eneida Oto; CAMPOS, Roselane Fátima. La ressignificación de la democracia escolar mediante el discurso gerencial: liderazgo, gestión democrática y gestión participativa. In: FELDFEBER, Myriam; OLIVEIRA, Dalila Andrade (comp.). Políticas educativas y trabajo docente: nuevas regulaciones ¿Nuevos sujetos? Buenos Aires: Noveduc, 2006. p. 221-237.

SOUZA, Celina Maria de. Democracia, participação social e funcionamento das instituições: situação e perspectivas da federalização do desenvolvimento. Revista de Administração Pública, Rio de Janeiro, v. 26, n. 3, p. 15-35, jul./set. 1992. 


\section{Elton Luiz Nardi}

Doutor em Educação pela Universidade do Vale do Rio dos Sinos (Unisinos). Professor Titular da Universidade do Oeste de Santa Catarina (Unoesc). Docente permanente do Programa de Pós-Graduação em Educação. Bolsista de produtividade em pesquisa do CNPq - Nível 2 E-mail: elton.nardi@unoesc. edu.br

\section{Marilda Pasqual Schneider}

Doutora em Educação pela Universidade Federal de Santa Catarina (UFSC). Professora Titular da Universidade do Oeste de Santa Catarina (Unoesc). Docente permanente do Programa de Pós-Graduação em Educação. E-mail: marilda.schneider@unoesc.edu.br

\section{Aline Bettiolo dos Santos}

Doutoranda em Educação pela Universidade do Oeste de Santa Catarina (Unoesc). Bolsista pela Coordenação de Aperfeiçoamento de Pessoal de Nível Superior. E-mail: a.bettiolo.santos@unoesc.edu.br

\section{Durlei Maria Bernardon Rebelatto}

Mestre em Educação pela Universidade do Oeste de Santa Catarina (Unoesc). Pedagoga do Instituto Federal de Santa Catarina (IFSC) - Campus Itajaí. E-mail: durlei.rebelatto@gmail.com. 